JOURNAL DE PHYSIQUE IV

Colloque C5, supplément au Journal de Physique II, Volume 5, juin 1995

\title{
Recent Trends in the Selection of Metal-Organic Precursors for MOCVD Process
}

F. Maury

Cristallochimie, Réactivité et Protection des Matériaux, CNRS/INPT, Ecole Nationale Supérieure de Chimie, 118 Route de Narbonne, 31077 Toulouse cedex, France

\begin{abstract}
The tremendous expansion of metal-organic chemical vapor deposition process (MOCVD) is accounted for its ability to deposit at low temperature a wide variety of thin film materials keeping advantages of the conventional CVD process. The design and the selection of suitably tailored metal-organic precursors is a fundamental key to develop successfully an MOCVD process. The criteria of selection of metal-organic precursors are critically reviewed and the problem of the carbon incorporation in the films is discussed. Advantages and disadvantages of employing single source metal-organic precursors instead of separate precursors for MOCVD of multi-components materials is discussed using results on the deposition of chromium nitride and $\beta-\mathrm{CoGa}$.
\end{abstract}

\section{INTRODUCTION}

Since several years metal-organic compounds are extensively used as molecular precursors for the chemical vapor deposition process (MOCVD). The success of this technique is mainly due to its versatility and to the increasing interest for the low temperature deposition processes. Correlatively, the increasing demand of various thin film materials for new industrial applications is also a substantial reason for the rapid development of MOCVD. Indeed, a wide variety of materials which could not be deposited by the conventional halide CVD process, because halide reactives do not exist or are not volatile, can now be grown by MOCVD. This includes metals and different multi-component materials such as semiconductor and intermetallic compounds as well as carbides, nitrides, oxides, borides, silicides and chalcogenides. Further significant advantages of MOCVD over physical processes are a capability for large scale production, an easier automation, a good conformal coverage, the selectivity and the ability to produce metastable materials.

In spite of these promising advantages, industrial applications of MOCVD process are still limited likely because the commercial availability of starting molecular compounds is insufficient. However, plenty of metal-organic precursors are tested in preliminary research works and proposed in the literature but the development of a new MOCVD process for the production of a desired thin film material requires an integrated approach involving the selection of the precursor and the reliable growth of high quality material (control of its composition, microstructure and thickness) possibly on a large scale. Usually, this requires thorough fundamental studies (thermodynamics, kinetics and reaction mechanisms) and, further, chemical engineering of the overall process (optimization of the reactor and the processing conditions possibly using modelling). Facing the abundance of metal-organic compounds that can be supplied by the chemists, the design and the selection of suitably tailored metal-organic precursor is a fundamental key to develop successfully an MOCVD process. 
Thus, much effort has been aimed at the synthesis of new molecular precursors. A fruitful overview is provided by several excellent reviews covering particular fields of MOCVD such as, for instance, epitaxial growth of semiconductor compounds [1-3], low temperature deposition of metals [4, 5] and ceramics [6]. Attempt to write an up-to-date review on the metal-organic compounds used for the growth of the different kind of materials, as this was done few years ago $[5,6]$, will be a tremendous work since the expansion of MOCVD is now becoming an explosion. It seems more useful to attempt to rationalize these cumulative literature reports.

The criteria of selection of metal-organic precursors are critically reviewed in this paper. The stringent requirements for molecular metal-organic compounds suitable for classical MOCVD and emerging techniques such as Photo-MOCVD and metal-organic molecular beam epitaxy (MOMBE) are discussed using our recent results and examples from the literature. Particular emphasis is placed on the problem of the carbon incorporation in the films. Advantages and disadvantages of employing single source metal-organic precursors instead of separate precursors for MOCVD of multi-components materials is discussed from results on the deposition of chromium nitrides and $\beta-\mathrm{CoGa}$.

\section{DESIGN OF METALORGANIC PRECURSORS FOR MOCVD}

The current state of knowledge of MOCVD process accumulated over many years allows to list the fundamental properties of an ideal precursor. Depending on the restrictions for the process, the general criteria of all precursors (section 2.1) can be slightly modified or completed by more specific requirements (section 2.2).

\subsection{General criteria of selection of precursors}

An ideal precursor should have (1) a good volatility (possibly higher than $10^{-1}$ Torr at $\sim 100$ $\left.{ }^{\circ} \mathrm{C}\right),(2)$ a good thermal stability during its evaporation and transport in the gas phase, (3) a high purity (it should be readily purifyable) and (4) it should decompose cleanly on pyrolysis without contamination of the growing film (e.g. by carbon). Moreover, it should be (5) non-toxic (like its decomposition by-products) and non-pyrophoric (to minimize fire hazard), (6) readily available in consistent quality and quantities at low cost, (7) liquid rather than gas or solid and (8) stable in its container over a long period since its rate of consumption is rather low. Before to introduce more specific criteria, some of the above ones merit a brief comment.

Many metal-organic molecules are sufficiently volatile to be transported in the gas phase from the bubbler to the deposition zone. Data on their volatility is of essential importance to engineer an MOCVD process. However, vapor pressure data are not frequently reported in the literature although several methods exist for their measurement such as direct methods [7-9], the Knudsen cell method [7,10] and the capillary gas chromatography method [11]. Enhancement of the volatility requires a minimization of the polarizability, dipoles and chiefly interactions between molecules of precursor in the condensed state (e.g. $\mathrm{H}$ bonds...). Obviously, ionic and covalent intermolecular bonds (polymer) kill the volatility. However, optimization of both simultaneously entropy and enthalpy change on vaporization is conflicting and therefore this is still achieved by rule of thumb. For instance, for non-polar compounds, smaller size is associated with higher vapor pressure. On the other hand, it was demonstrated using $\beta$-diketonate complexes [7] that substitution of hydrogen in acetyl groups by a methyl group increases the volatility because of the shielding effect due to these bulky ligands. Similarly, substitution of hydrogen by fluorine decreases the number of $\mathrm{H}$ bonds and increases the volatility. Thus, certain ligands contribute efficiently to increase the volatility, e.g. carbonyl, cyclopentadienyls, arenes... Most of metallocene complexes have a sufficient volatility and have been used successfully as MOCVD precursor (Table 1). It is noteworthy to mention here that addition of some ligands or other organic compounds in the carrier gas allows a complete vaporization of the precursor and increases its vapor pressure [7]. However the mechanism of this enhancement is not clear.

It is hazardous to handle extremely toxic gases stored in high pressure steel cylinders but, fortunately, metal-organic compounds are either liquid or solid. However, it is preferable the 
precursor be liquid at the bubbler temperature used. Indeed when a solid reagent is used the pick-up is variable during the run because of changing surface area of solid as it is consumed. Interestingly, substitution of some ligands or part of some ligands can decrease drastically the melting point without changing significantly the vapor pressure and the stability of the precursor, i.e. its decomposition mechanism. This is achieved when we substitute an hydrogen of the cyclopentadienyl by a methyl group (Table 1). Similarly, the heteroleptic organoindium compounds InMe2Et is a liquid which has given promising results for the growth of InP epilayers compared with the traditional solid source InMe3 [12]. However its long-term stability is doubtful due to disproportionation equilibrium whereby InMe 3 and InEt3 are formed [13].

\begin{tabular}{|l|ll|l|l|}
\hline Compound & \multicolumn{2}{|c|}{ p(Torr)/80 ${ }^{\circ} \mathbf{C}$} & \multicolumn{2}{|c|}{ m.p. $\left({ }^{\circ} \mathbf{C}\right)$} \\
& $\mathbf{R}=\mathbf{H}$ & Ref. & $\mathbf{R}=\mathbf{H}$ & $\mathbf{R}=\mathbf{M e}$ \\
\hline$\left(\eta^{5}-\mathrm{RC}_{5} \mathrm{H}_{4}\right)_{2} \mathrm{~V}$ & $2.010^{-2}$ & {$[14]$} & 168 & $26-8$ \\
$\left(\eta^{5}-\mathrm{RC}_{5} \mathrm{H}_{4}\right)_{2} \mathrm{Cr}$ & - & - & $172-3$ & $35 \quad[22]$ \\
$\left(\eta^{5}-\mathrm{RC}_{5} \mathrm{H}_{4}\right)_{2} \mathrm{Mn}$ & $7.410^{-1}$ & {$[15]$} & 173 & $61-2$ \\
$\left(\eta^{5}-\mathrm{RC}_{5} \mathrm{H}_{4}\right)_{2} \mathrm{Fe}$ & $7.010^{-1}$ & {$[16]$} & 173 & $37.5-38$ \\
$\left(\eta^{5}-\mathrm{RC}_{5} \mathrm{H}_{4}\right)_{2} \mathrm{Co}$ & $3.410^{-1}$ & {$[17]$} & 174 & $35-6$ \\
$\left(\eta^{5}-\mathrm{RC}_{5} \mathrm{H}_{4}\right)_{2} \mathrm{Ni}$ & 1.0 & {$[18]$} & $171-3$ & $36-8$ \\
$\left(\eta^{5}-\mathrm{RC}_{5} \mathrm{H}_{4}\right)_{2} \mathrm{Ru}$ & $1.810^{-1}$ & {$[19]$} & $199-200$ & $61-3$ \\
$\left(\eta^{5}-\mathrm{RC}_{5} \mathrm{H}_{4}\right)_{2} \mathrm{Os}$ & $6.510^{-2}$ & {$[19]$} & $229-30$ & $82-3$ \\
\hline$\left(\eta^{5}-\mathrm{RC}_{5} \mathrm{H}_{4}\right)_{2} \mathrm{Mg}$ & 2.8 & {$[20]$} & 176 & 27 \\
$\left(\eta^{5}-\mathrm{RC}_{5} \mathrm{H}_{4}\right)_{3} \mathrm{Nd}$ & - & - & 380 & 165 \\
$\left(\eta^{5}-\mathrm{RC}_{5} \mathrm{H}_{4}\right)_{2} \mathrm{PtMe}$ & 4.8 & {$[21]$} & 106 & 30 \\
$\left(\eta^{5}-\mathrm{RC}_{5} \mathrm{H}_{4}\right) \mathrm{Mn}(\mathrm{CO})_{3}$ & - & - & $76.8-77.1$ & 1.5 \\
{$\left[\left(\eta^{5}-\mathrm{RC}_{5} \mathrm{H}_{4}\right) \mathrm{Fe}(\mathrm{CO})_{2} \mathrm{~d}_{2}\right.$} & - & - & 194 & 102 \\
\hline
\end{tabular}

Table 1: Comparison of melting points of $\left(\eta^{5}-\mathrm{Cp}\right)$ and $\left(\eta^{5}-\mathrm{MeCp}\right)$ derivatives. Most of these complexes were used as MOCVD precursor. Data are from [23] excepted the vapor pressure data. Isostructural metallocenes are gathered in the top part of the table.

\subsection{Specific requirements}

Depending on the constraints related to the nature of the desired material and the restrictions of the process (nature of the substrate, limited range of experimental conditions...), additional specific criteria must be taken into account. For instance, in many CVD processes the presence of halogen is detrimental because it can promote corrosion of the film and/or of the substrate. We can mention also that certain MOCVD process must work under low pressure, for example to achieve a good thickness uniformity of films deposited in large scale reactor and/or on substrate with a complex shape.

\subsubsection{Epitaxial techniques}

The traditional precursors for metal-organic vapor phase epitaxy (MOVPE) of semiconductor compounds (III-V and II-VI materials) are alkyl derivatives of the main group elements (Al, Ga, In...) and hydrides of elements from columns 14-16 ( $\left.\mathrm{As}_{3} \ldots\right)$. The important works done in the design of molecules for this process aimed at fulfilling the above stringent requirements, chiefly the purity and the reactivity of the precursor. This effort is largely profitable to other MOCVD 
processes. Thus, original problems associated to the purity of the alkyl sources have been overcome by the use of new synthesis routes [24] and purification methods [25, 26].

In the methyl-based chemistry of group III sources (elements from the column 13), the minimization of the carbon incorporation in the epilayers requires the use of both low growth temperature and high excess of hydride. A convenient alternative solution is to use complexes with ligands that are able to undergo $\beta$-hydrogen elimination $(e . g . \mathrm{Et}, t$-Bu) or which do not contain direct $\mathrm{M}-\mathrm{C}$ bond (e.g. $\mathrm{H}_{3} \mathrm{Al}$.NMe 3 ) [27]. For this reason, the use of GaEt3 is mainly restricted to low pressure MOVPE or MOMBE [28].

From a general point of view, the use of two separate sources for the growth of a compound material involves two principal requirements to be able to control carefully the film stoichiometry: $(i)$ they should have roughly the same thermal stability and (ii) they should be chemically inert one towards the other to avoid unwanted gas phase reactions. Alternatives to $\mathrm{AsH}_{3}$ and $\mathrm{PH}_{3}$ are required because, in addition to safety reason, these hydrides do not fulfil these properties. Partially substituted arsines and phosphines are promising candidates since they are liquid compounds with a lower thermal stability and toxicity than their parent hydrides $[1,29]$. Consequently, such molecules are also attractive for MOMBE since they can be used without pre-cracking prior to injection in the chamber, contrarily to $\mathrm{AsH}_{3}$, as this was demonstrated with $\mathrm{PhAsH}_{2}$ [28] and recently confirmed by us with Et2 $\mathrm{AsH}_{2}$ [30].

The precursors used for the growth of III-V (and II-VI) semiconductors are Lewis acid (e.g. $\mathrm{GaR}_{3}$ ) and Lewis base (e.g. AsH3) compounds and therefore they can be involved in gas phase pre-reactions to form adducts $\left(e . g . \mathrm{R}_{3} \mathrm{Ga} . \mathrm{AsH}_{3}\right)$ and sometimes, subsequently, undesirable homogeneous nucleation (e.g. $\left.[\mathrm{RGa}-\mathrm{AsH}]_{\mathrm{n}}\right)$. In the 80 's, prolific works on alternative sources aimed at solving this problem of reactivity. Thus, adduct compounds were proposed to be used as replacement for group III alkyls since their reactivity towards the hydride is blocked [31-33]. This approach is now more appropriate to the chemistry of In and Al [27]. Adducts and molecules featuring a stronger covalent bond between the elements III and V were proposed to be used directly as single source precursor [2, 3, 34]. Limitation of the adducts to be used as single source is their dissociation since, when this occurs, the atomic ratio V/III in the reaction zone is unfavourable and leads to films with poor quality. Limitation of the covalent compounds originates from their purity, their volatility and chiefly their molecular size. Indeed, these dimeric or trimeric molecules have likely a low surface diffusion rate due to their bulky structure that leads to films with a poor crystallinity $[3,34,35]$. However, even if they have a low volatility for MOVPE process, this is not a major drawback for MOMBE and they could be potential single sources for this process.

Although the presence of halide atoms is often excluded in metal-organic compounds, they are sometimes essential for the process, like for the selective area epitaxy of GaAs. Indeed, like for the halide process which uses $\mathrm{AsCl}_{3}$ or $\mathrm{HCl}$ addition, a selective growth is achieved using $\mathrm{Et}_{2} \mathrm{GaCl}_{\mathrm{AsH}}$ [36] owing to the formation of the volatile $\mathrm{GaCl}$ species which can readily desorb from the mask surface preventing a high supersaturation and the subsequent nucleation on this surface.

\subsubsection{Photo-assisted MOCVD}

It is well known that UV radiation can be used to enhance the fragmentation of metal-organic compounds. As a consequence, photo-assisted MOCVD processes are more and more used to decrease the growth temperature and to develop new selected area deposition processes. The deposition is enhanced if the precursor absorbs the light as efficiently as possible. So, the main constraint is the limited number of light sources which emit sometimes at wavelengths well away from the maximum absorption of the precursor. Consequently, the molecular precursors should have, in addition to the general requirements, a strong absorption band with a maximum which matches the wavelength of the available UV sources.

The wavelength of the light absorbed by a molecule depends on the nature the chemical bonds. For example, $\sigma$-electrons are tightly bound to the molecule, therefore the energy gap between the ground state and excited state is large, resulting in an absorption band at low 
wavelength $(<230 \mathrm{~nm})$. By contrast, $\pi$-electrons are less tightly held and therefore the corresponding absorption band shifts to higher wavelengths. A conjugated structure is seen as a resonant mixture of equivalent contributing structures so the energy of the structure is a weighted average of the energies of the contributing structures. Fig. I shows that these fundamental principles have been successfully applied to monitor the maximum of the absorption band of alkoxy aluminium $\beta$-diketonates [37]. Metal diketonates absorb strongly above $250 \mathrm{~nm}$ due to their aromatic character. Substitution at R1 and R2 by bulky groups (inset of Fig. 1) reduces the delocalisation of $\pi$-electrons due to steric effect and shifts the absorption to higher wavelengths. Conversely, substitution by alkoxy groups inhibits the formation of the resonant structure and the absorption occurs at shorter wavelengths.

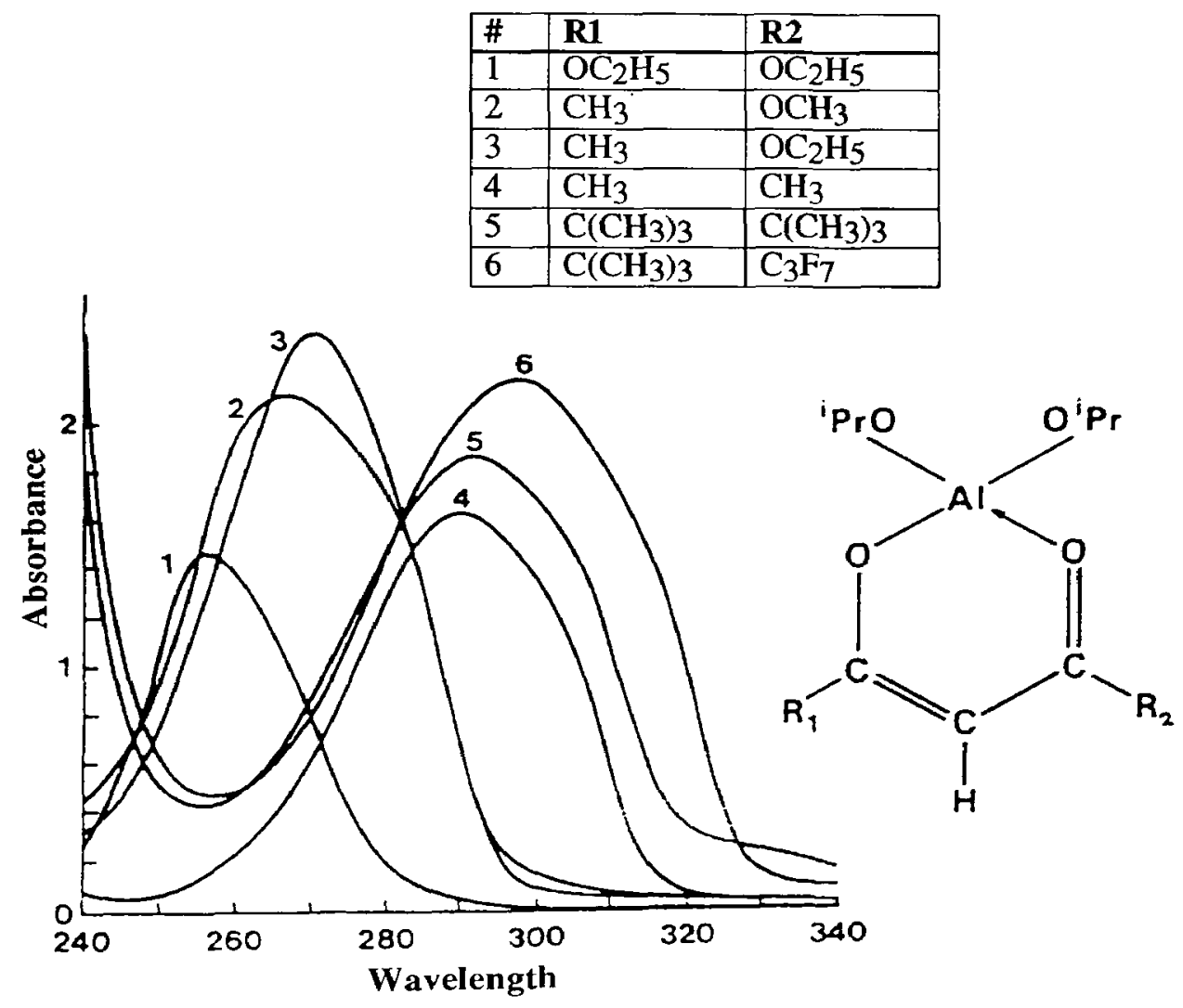

Fig. 1: UV absorption spectra of alkoxy aluminium $\beta$-diketonates (after [37]).

\subsubsection{Thermal MOCVD}

The synthesis of tailored metal-organic precursor is a stimulating challenge for chemists although the degree of freedom in the design of molecule is limited. In addition to its volatility, the more stringent requirement for an MOCVD precursor is obviously its ability to be cleanly decomposed at low temperature to the desired material. Specific criteria for the precursor may be dictated by its decomposition mechanism. Indeed, each element has its own chemistry and the choice of the ligands is essentially justified from a comparison of the different bond strengths and the knowledge of decomposition mechanisms of its class of compounds. 
If the alkyl derivatives of the main group elements are the single class of compounds which supplies suitable precursors, those of transition metals are generally unsuitable because of their low kinetic stability. However, as against this they offer a greater variety of ligands leading to more complex mechanisms. The nature of the ligand and the type of metal-ligand bonds determine and control the decomposition pathway which converts the precursor to the thin film. However to know which ligands are useful and which are deleterious for the growth of a pure desired material, we should increase our knowledge on the reaction mechanisms. The following sections attempt to afford a further insight into the problem of the carbon incorporation and the suitability of using single source precursor for the deposition of multi-component materials.

\section{CONTROL OF THE CARBON INCORPORATION IN MOCVD FILMS}

The main drawback of MOCVD is contamination of deposit by carbon derived from the ligands. This section has not the pretension to solve this crucial problem but its goal is to sensitize and instigate ideas from some solutions reported in the literature. Two different cases may occur depending whether or not the carbides are thermodynamically stable in the experimental conditions. For the noble metal and most of the main group elements the carbides are not stable and then carbon incorporation results in a contamination by adventitious free carbon (often amorphous or graphitic and more rarely organic). The non-noble transition metals have a high affinity for the carbon and frequently several stable carbide phases exist for each element. So, in addition to a contamination by free $\mathrm{C}$ still possible, the problem is to control the growth of the desired carbide phase. Two routes seem to be explored according as the preferential requirement for the precursor is its ability (i) to undergo a clean stripping of its ligands by an intrinsic mechanism or (ii) to decompose in relevant conditions applicable owing to its favourable physico-chemical properties (volatility, stability...), for example, under atmospheric pressure and/or involving a reaction with a further reagent.

Regarding the first route, the thermal decomposition of metal-organic compounds can occur by numerous mechanisms and for each precursor, or family of precursor, we must find the best pathway whereby the ligands are removed cleanly without incorporating any carbon in the film. For instance, when a ligand undergoes the classical $\beta$-hydrogen elimination (reaction 1 ) this facilitates its removal as stable olefin and reduces the carbon incorporation (e.g. GaEt3, $\mathrm{Al}-i \mathrm{Bu} 3 . .$.$) .$

$$
\mathrm{M}-\mathrm{CH}_{2} \mathrm{CHR}_{2} \quad \mathrm{M}-\mathrm{H}+\mathrm{H}_{2} \mathrm{C}=\mathrm{CR}_{2}
$$

However, many other elimination reactions are known in organometallic chemistry including intramolecular and radical pathways.

An interesting approach is to attempt to classify the reactivity of different ligands against the same metal. For instance, thermal decomposition of $\left(\mathrm{C}_{7} \mathrm{H}_{8}\right) \mathrm{Cr}(\mathrm{CO})_{3}$ leads to the deposition of chromium carbide films with $9-12 \mathrm{wt} \%$ carbon. From ${ }^{13} \mathrm{C}$ labelling experiments, the authors have demonstrated that the majority of the incorporated $C(>85 \%)$ originated from the cycloheptatriene ring [38]. This means that the reactivity of $\pi$-arene ligands seems to be greater than that of carbonyls to form chromium carbide films. From similar experiments and using model precursors, it should be possible to classify the ability of the different ligands to be cleanly removed from each metal.

Ideally, the simplest elimination mechanism occurs when the ligand is itself a stable molecule which can be released after cleavage of the metal-ligand bond $\left(e . g . \mathrm{CO}, \mathrm{C}_{6} \mathrm{H}_{6}\right.$, alkenes...). In such complexes the metal-ligand bond is preferentially broken since this is generally the weakest bond of the molecule. In that case, the carbon contamination results from unwanted side reactions involving the ligand. Thus, using carbonyls precursors, carbon contamination originates both from the disproportionation reaction 2 and the dissociative chemisorption of $\mathrm{CO}$.

$$
2 \mathrm{CO} \quad \mathrm{CO}_{2}+\mathrm{C}
$$

For example, in the chromium deposition using $\mathrm{Cr}(\mathrm{CO})_{6}$, occurrence of reaction 2 is limited if $\mathrm{CO}$ groups are rapidly removed from the reaction zone that is achieved using a high total flow 
rate [39] or under low pressure [40-42]. Furthermore, since this is an homogeneous reaction, the use of a cold wall reactor allows to minimize this reaction [39-42]. Other works have shown that addition of a reagent in the gas phase such as $\mathrm{CO}_{2}$ [39], $\mathrm{H}_{2} \mathrm{O}$ [40] and $\mathrm{H}_{2} \mathrm{~S}$ [41] is also a convenient solution which concerns the second route (reaction with a further reagent). If addition of $\mathrm{CO}_{2}$ shifts the equilibrium 2 towards the left side, the two other reagents inhibit likely the chemisorption of $\mathrm{CO}$ but their role is not fully understood. These interesting solutions can be generalised to limit the occurrence of homogeneous reactions but heterogeneous side decomposition of the ligands is more difficult to control.

According to this promising route, the deposition of pure transition metal seems possible, even if the carbide phases are thermodynamically stable, by addition of reagents in the gas phase during the growth. Indeed, MOCVD using bis(arene)chromium compounds leads usually to the growth of a mixture of chromium carbides more or less contaminated by free carbon [22] and it was claimed that addition of $\mathrm{HI}$ [43] or $\mathrm{C}_{6} \mathrm{Cl}_{6}$ [44] in the gas phase suppresses the codeposition of carbon leading to pure $\mathrm{Cr}$ metal. With the same objective, we have deposited recently, pure $\mathrm{Cr}$ metal films by pyrolysis of bis(benzene)chromium under atmospheric pressure and using a high partial pressure of hydrogen, in agreement with the trend predicted by a thermodynamic simulation performed for the system $\mathrm{Cr}-\mathrm{C}-\mathrm{H}$ [45]. This indicates that when the carbides are stable, the metal deposition is possible either using a kinetically controlled process (labile ligands, low temperature, catalyst) or using an efficient reaction with $\mathrm{H}_{2}$ to displace the carbon from the film to the gas phase in the form hydrocarbons in conditions predicted by the thermodynamics (atmospheric pressure, low molar fraction).

Many works report that highly pure noble metals, e.g. Pt [21], Ir [46], Rh..., are best obtained in the presence of $\mathrm{H}_{2}$ from precursors containing only hydrocarbon ligands which can be removed as saturated hydrocarbons. In absence of $\mathrm{H}_{2}$, the films are highly contaminated by carbon. By contrast, the films of non-noble metals, e.g. $\mathrm{Cu}, \mathrm{Cr}, \mathrm{W} \ldots$, have tendency to retain a large amount of carbon even in presence of $\mathrm{H}_{2}$ and the ligands are removed as unsaturated hydrocarbons. It was remarked that the first class of metals are Fischer-Tropsch active metals, i.e. they are able to catalyze the hydrogenolysis of $\mathrm{CO}$ to hydrocarbon and $\mathrm{H}_{2} \mathrm{O}$ as well as methanation of surface carbon in presence of $\mathrm{H}_{2}$ [47]. The inefficiency of $\mathrm{H}_{2}$ to reduce the carbon level in the films of the second class of metals have been frequently reported (see for example [22] for chromium films). When a metal is not a Fischer-Tropsch catalyst, the carrier gas molecules may promote the surface decomposition of the ligands or some of the hydrocarbons formed, interfering with their removal, which is then more efficient under high vacuum. Such a mechanism is known as the collision-induced dissociative chemisorption and as been described as "chemistry with a hammer" [48]. Exploring the second route to suppress the carbon contamination, H. D. Kaesz et al. wondered if "the presence of a Fischer-Tropsch active metal can serve as a catalyst for the clean deposition of a non-Fischer-Tropsch active metal in presence of hydrogen" [47]. Recently, they have demonstrated the validity of this idea since they have shown that co-deposition of ca 3 at\% $\mathrm{Pt}$ from $\mathrm{CpPtPMe} 3$ under $\mathrm{H}_{2}$ atmosphere suppressed effectively the carbon incorporation in a deposit of $\mathrm{W}$ metal from $\mathrm{Cp}_{2} \mathrm{WH}_{2}$ at 350 ${ }^{\circ} \mathrm{C}[49]$.

\section{SINGLE SOURCE VERSUS MULTI-SOURCE PRECURSORS FOR MOCVD OF COMPOUND MATERIALS}

\subsection{Is the composition or the structure the main factor of a single source?}

A single source precursor is a metal-organic molecule which contains all the desired elements for the growth of a compound material, possibly with the film stoichiometry. Such a molecular compound allows a good control of the gas phase composition up to the deposition zone and a simplification of the reactor design and processing conditions. The attractive idea of using single source precursors already containing direct chemical bond between the elements required for the material has been applied successfully to the growth of different kinds of materials, $e \cdot g$. III-V semiconductors $[2,3,34]$, AIN ceramic films [50], GaS [51] and many others. 
Ideally the structure of the precursor is configured in such a way that the core formed by the essential elements resemble that of the material as much as possible (Fig. 2). To keep benefit of this molecular structure, the bonds between the elements of the core must be stronger than those between the core and the organic ligands. Fig. 2a shows an example of single source designed for the growth of AIN [50]. When the organic groups bound to the core are removed cleanly by selective bond breaking, it is possible to built a material from the structural unit represented by this core. Then, the structure of the material is strongly influenced by the molecular structure of the single source. Fig. 2b highlights this approach since a metastable cubic GaS phase featuring a cell constituted of eight cluster cores has been grown using the gallium chalcogenide cubane $[(t-\mathrm{Bu}) \mathrm{GaS}]_{4}[51]$.

If the bond strengths between the elements of the core are similar or weaker than those between the core and the organic ligands, then the precursor undergoes a complex nonselective decomposition and the advantages of a single source are lost. This behavior has been observed for many single sources selected, for example, for the growth of oxides and chiefly nitrides (e.g. tetrakis(dialkylamido) complexes) since addition of $\mathrm{O}_{2}$ and $\mathrm{NH}_{3}$ were required, respectively, to attain the correct stoichiometry.

If a selective bond breaking of the core-ligand bonds occurs the process will be likely kinetically controlled while if a kinetic mechanism is not strongly favoured then the reaction will proceed in the direction indicated by the thermodynamics. This last case occurs, for instance, when the film composition is not the same than that of the precursor but is in agreement with the thermodynamic prediction. If the deposition process must not be controlled by the kinetics, e.g. for an epitaxial growth, the dominant factor for the single source precursor is its composition rather than its structure and a strong bond between the essential elements is not required: they can be associated only by a bridging ligand [52].

(a)



$\left(\left(\mathrm{CH}_{3}\right)_{2} \mathrm{AlNH}_{2}\right]_{3}$

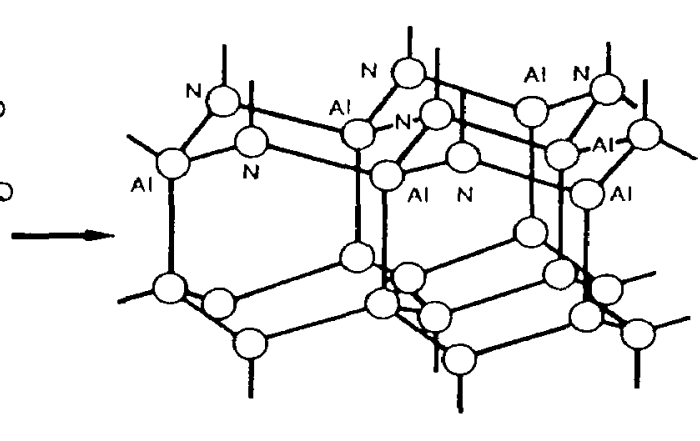

AIN

(b)
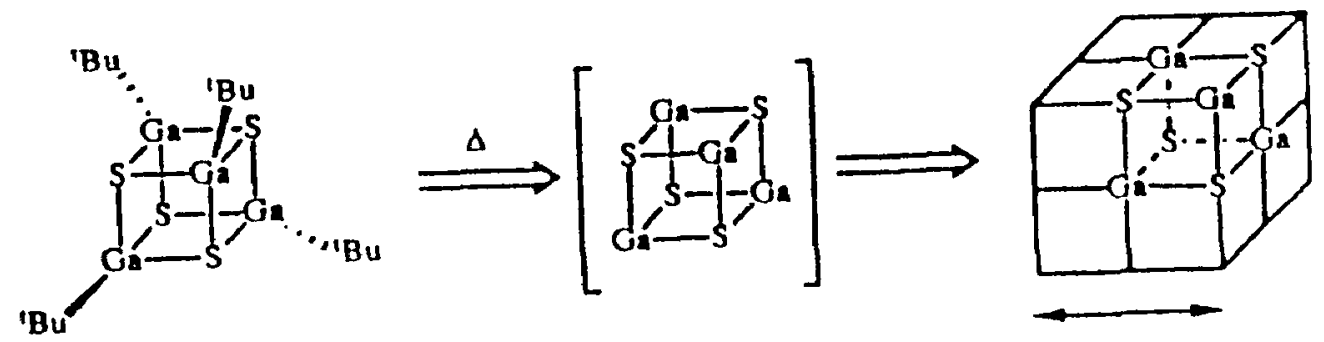

Fig. 2: Examples of single sources showing the influence of the precursor structure on that of the deposited material, (a) AlN [50], (b) GaS [51]. 


\subsection{Chromium nitride deposition}

The thermodynamic analysis briefly described in this section shows that this approach provides fruitful informations for the choice of the metal-organic precursor and subsequently the determination of the best deposition conditions required for the growth of a desired phase. A complex equilibrium calculation based on the minimization of the Gibbs energy of the whole system was performed for the system $\mathrm{Cr}-\mathrm{N}-\mathrm{C}-\mathrm{H}$ using a computer program to predict the composition of the coating formed by pyrolysis of different organochromium sources. The goal of this work was to find the conditions for the growth of the hexagonal hard phase $\mathrm{Cr}_{2} \mathrm{~N}$. In this method [53], all the gaseous and solid species which can be formed during the chemical reaction must be taken into account and its reliability depends strongly on the validity of the thermodynamic data [54]. The calculation was possible after the determination of the Gibbs free energy of the solid solution $\mathrm{Cr}_{2}\left(\mathrm{~N}_{\mathrm{x}} \mathrm{C}_{1-\mathrm{x}}\right)$ versus the temperature and the composition [55]. The chemical species considered were $\mathrm{CH}, \mathrm{CH}_{2}, \mathrm{CH}_{3}, \mathrm{CH}_{4}, \mathrm{C}_{2} \mathrm{H}_{2}, \mathrm{C}_{2} \mathrm{H}_{4}, \mathrm{C}_{2} \mathrm{H}_{6}, \mathrm{C}_{3} \mathrm{H}_{4}, \mathrm{C}_{3} \mathrm{H}_{8}, \mathrm{C}_{4} \mathrm{H}_{2}$, $\mathrm{C}_{4} \mathrm{H}_{6}, \mathrm{C}_{6} \mathrm{H}_{6}, \mathrm{CHN}, \mathrm{CN}, \mathrm{CN}_{2}, \mathrm{C}_{2} \mathrm{~N}, \mathrm{C}_{2} \mathrm{~N}_{2}, \mathrm{NH}, \mathrm{NH}_{2}, \mathrm{NH}_{3}, \mathrm{~N}_{2} \mathrm{H}_{2}, \mathrm{~N}_{2} \mathrm{H}_{4}, \mathrm{H}, \mathrm{H}_{2}, \mathrm{~N}, \mathrm{~N}_{2}, \mathrm{CrN}, \mathrm{Cr}$ in the gas phase and $\mathrm{Cr}, \mathrm{Cr}_{23} \mathrm{C}_{6}, \mathrm{Cr}_{7} \mathrm{C}_{3}, \mathrm{Cr}_{3} \mathrm{C}_{2}, \mathrm{CrN}, \mathrm{Cr}_{2} \mathrm{~N}, \mathrm{Cr}_{2}\left(\mathrm{~N}_{\mathrm{x}} \mathrm{C}_{1-\mathrm{x}}\right)$ and $\mathrm{C}$ in the condensed phases. Their thermodynamic data were taken from a data bank [56].

Calculations were performed for the input gas mixtures $\mathrm{Cr}\left(\mathrm{C}_{6} \mathrm{H}_{6}\right)_{2} / \mathrm{NH}_{3} / \mathrm{H}_{2} / \mathrm{He}$ and $\mathrm{Cr}\left(\mathrm{NEt}_{2}\right)_{4} / \mathrm{H}_{2} / \mathrm{He}$ to simulate the use of a dual precursor system and that of a single source precursor, respectively. Obviously, this analysis assumes that the process is controlled by the thermodynamic equilibrium and that other phenomena like kinetics and diffusion are neglected. The organochromium compounds were assumed to be completely decomposed at $527^{\circ} \mathrm{C}$ that is in satisfactory agreement with experimental observations for $\mathrm{Cr}\left(\mathrm{C}_{6} \mathrm{H}_{6}\right)_{2}$ [57] and for $\mathrm{Cr}\left(\mathrm{NEt}_{2}\right)_{4}$ which was found less stable.

Typical results of the calculation for the single source system $\mathrm{Cr}\left(\mathrm{NEt}_{2}\right)_{4} / \mathrm{H}_{2} / \mathrm{He}$ are reported in Table 2. First, the hexagonal $\mathrm{Cr}_{2} \mathrm{~N}$ phase deposited by CVD at high temperature [58] is not obtained in the explored conditions using this single source precursor. The only chromium nitride obtained is the cubic phase $\mathrm{CrN}$. This occurs only under atmospheric pressure and using a large excess of $\mathrm{H}_{2}$. Clearly it appears that the reduced pressure facilitates both the formation of chromium carbide (or carbo-nitride) and the contamination by free carbon.

\begin{tabular}{|c|c|c|c|c|}
\hline $\begin{array}{c}\text { Total pressure } \\
\text { (atm) }\end{array}$ & $\begin{array}{c}\mathrm{He} / \mathrm{Cr}\left(\mathrm{NEt}_{2}\right)_{4} \\
=1\end{array}$ & $\begin{array}{c}\mathrm{He} / \mathrm{Cr}(\mathrm{NEt})_{2} 4 \\
=100\end{array}$ & $\begin{array}{c}\mathrm{H}_{2} / \mathrm{Cr}\left(\mathrm{NEt}_{2}\right)_{4} \\
=1\end{array}$ & $\begin{array}{c}\mathrm{H}_{2} / \mathrm{Cr}\left(\mathrm{NEt}_{2}\right)_{4} \\
=1000\end{array}$ \\
\hline $10^{-3}$ & $\mathrm{Cr}_{3} \mathrm{C}_{2}+\mathrm{C}$ & \multirow{3}{*}{$\begin{array}{l}\mathrm{Cr}_{3} \mathrm{C}_{2}+\mathrm{C} \\
\mathrm{Cr}_{3} \mathrm{C}_{2}+\mathrm{C} \\
\mathrm{Cr}_{3} \mathrm{C}_{2}+\mathrm{C}\end{array}$} & \multirow[t]{2}{*}{$\mathrm{Cr}_{3} \mathrm{C}_{2}+\mathrm{C}$} & \multirow{2}{*}{$\begin{array}{c}\mathrm{Cr}_{3} \mathrm{C}_{2}+\mathrm{C} \\
- \\
\end{array}$} \\
\hline $5 \times 10^{-3}$ & $\mathrm{Cr}_{2}(\mathrm{~N}, \mathrm{C})+\mathrm{C}$ & & & \\
\hline $10^{-2}$ & $\mathrm{Cr} 2(\mathrm{~N}, \mathrm{C})+\mathrm{C}$ & & \multirow{2}{*}{$\begin{array}{c}\mathrm{Cr}_{2}(\mathrm{~N}, \mathrm{C})+\mathrm{C} \\
-\end{array}$} & \multirow{2}{*}{$\begin{array}{c}\mathrm{Cr}_{2}(\mathrm{~N}, \mathrm{C})+\mathrm{C} \\
-\end{array}$} \\
\hline $5 \times 10^{-2}$ & $\mathrm{CrN}+\mathrm{C}$ & $\mathrm{Cr}_{2}(\mathrm{~N}, \mathrm{C})+\mathrm{C}$ & & \\
\hline $10^{-1}$ & $\mathrm{CrN}+\mathrm{C}$ & $\mathrm{CrN}+\mathrm{C}$ & \multirow{3}{*}{$\begin{array}{c}\mathrm{CrN}+\mathrm{C} \\
- \\
\mathrm{CrN}+\mathrm{C}\end{array}$} & $\mathrm{CrN}+\mathrm{C}$ \\
\hline $5 \times 10^{-1}$ & $\mathrm{CrN}+\mathrm{C}$ & $\mathrm{CrN}+\mathrm{C}$ & & - \\
\hline & $\mathrm{CrN}+\mathrm{C}$ & $\mathrm{CrN}+\mathrm{C}$ & & $\mathrm{CrN}$ \\
\hline
\end{tabular}

Table 2: Theoretical influence of the total pressure and the input gas phase composition (mole fraction ratio) on the nature of the condensed phases deposited at $527{ }^{\circ} \mathrm{C}$ from the system $\mathrm{Cr}(\mathrm{NEt} 2)_{4} / \mathrm{H}_{2} / \mathrm{He}$.

Preliminary attempt to verify this result failed due to premature decomposition of $\mathrm{Cr}\left(\mathrm{NEt}_{2}\right)_{4}$ in the bubbler. However this is in agreement with results reported using the related 
alkylamide chromium compound $\mathrm{Cr}(\mathrm{N}-i \mathrm{Pr} 2) 3$ since the films deposited under reduced pressure contained 29 at.\% carbon [59]. Furthermore, there is a parent chemistry between amido complexes of $\mathrm{Ti}$ and $\mathrm{Cr}$ and it has been found that films deposited using $\mathrm{Ti}\left(\mathrm{NMe}_{2}\right) 4[60,61]$ and Ti(NEt2)4 [61] are heavily contaminated with carbon that is consistent with our prediction using the chromium derivative. In fact, reasonably pure metal nitride films prepared using tetrakis(dialkyamido)metal complexes requires addition of $\mathrm{NH}_{3}$. This was demonstrated for TiN $[62,63]$ and also for $\mathrm{Zr}, \mathrm{Hf}[62], \mathrm{Nb}, \mathrm{Ta}[64]$ and $\mathrm{V}[64,65]$. Investigation of reaction mechanisms $[64,66]$ and isotopic labelling experiments [67] have shown that a transamination gas-phase reaction between $\mathrm{M}\left(\mathrm{NR}_{2}\right)_{4}$ and $\mathrm{NH}_{3}$ is an important feature to deposit metal nitride films with a low carbon content.

According to these results, the single source route has not been retained for the growth of chromium nitride by low pressure MOCVD and the co-pyrolysis of $\mathrm{Cr}\left(\mathrm{C}_{6} \mathrm{H}_{6}\right)_{2}$ and $\mathrm{NH}_{3}$ has been preferred. An example of deposition diagram calculated for the system $\mathrm{Cr}\left(\mathrm{C}_{6} \mathrm{H}_{6}\right)_{2} / \mathrm{NH}_{3} / \mathrm{He}$ at $527^{\circ} \mathrm{C}$ and under a reduced pressure of $5 \times 10^{-3} \mathrm{~atm}$ is presented in Fig. 3. By increasing the $\mathrm{NH}_{3}$ partial pressure, $\mathrm{Cr}_{3} \mathrm{C}_{2}, \mathrm{Cr}_{2}(\mathrm{~N}, \mathrm{C})$ and the cubic phase $\mathrm{CrN}$ are successively obtained. The large excess of ammonia necessary to deposit the cubic $\mathrm{CrN}$ phase is noteworthy and is accounted for the high thermal stability of ammonia $\left(\mathrm{NH}_{3} / \mathrm{Cr}\left(\mathrm{C}_{6} \mathrm{H}_{6}\right)_{2}>100\right)$. All these phases are contaminated by free carbon probably owing to the important atomic ratio $\mathrm{C}: \mathrm{Cr}(12: 1)$ in the starting molecule. This $\mathrm{C}$ excess cannot be completely eliminated in the gaseous by-products using the hydrogen coming from both $\mathrm{NH}_{3}$ and the decomposition of aromatic ligands. Large values of the ratio $\mathrm{H}_{2} / \mathrm{Cr}\left(\mathrm{C}_{6} \mathrm{H}_{6}\right)_{2}$ are necessary to remove the free $\mathrm{C}$ from the $\mathrm{CrN}$ coatings to the gas phase in the form of $\mathrm{CH}_{4}$, but such conditions did not lead to adequate growth rates. The free $\mathrm{C}$ co-deposited with $\mathrm{CrN}$ was identified at the grain boundaries [68]. Table 3 shows the good agreement between this prediction and experimental results.

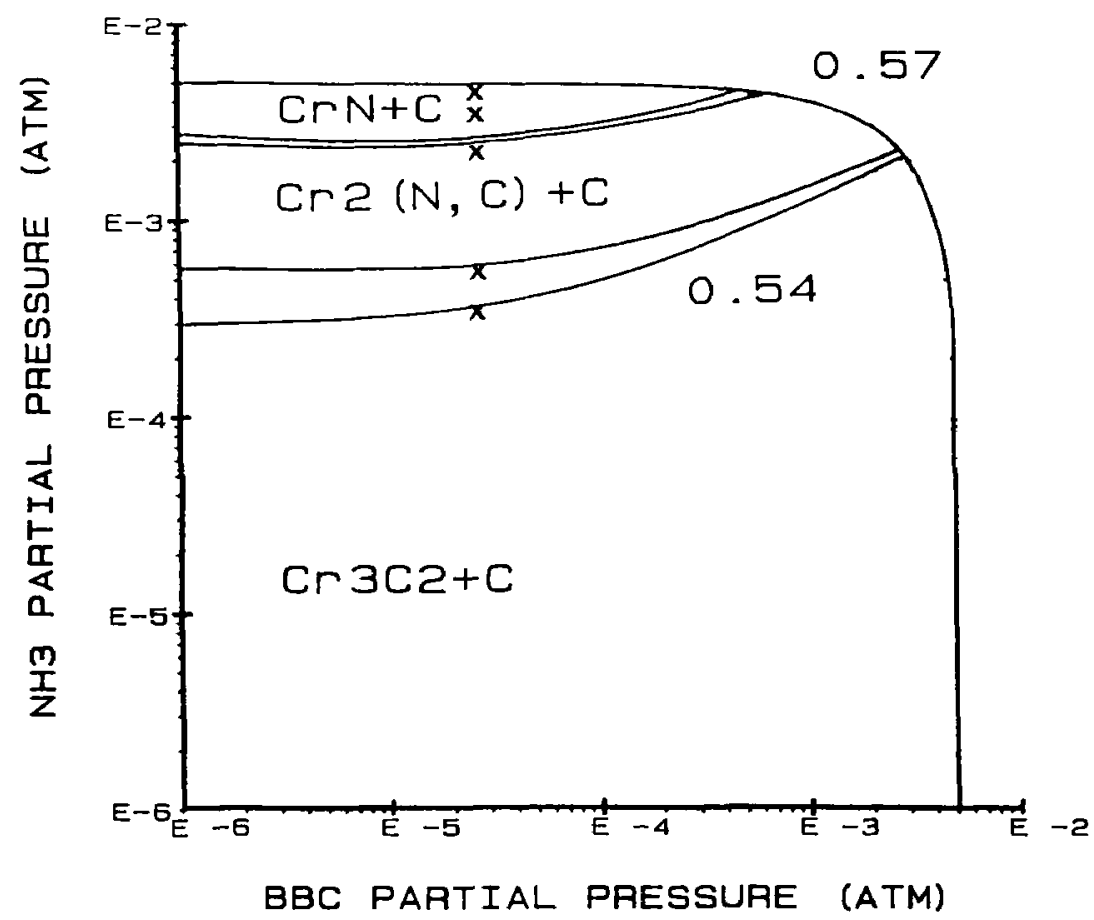

Fig. 3: Calculated deposition diagram for the system $\mathrm{Cr}\left(\mathrm{C}_{6} \mathrm{H}_{6}\right)_{2} / \mathrm{NH}_{3} / \mathrm{He}$ at $527^{\circ} \mathrm{C}$ and $5 \times 10^{-3}$ atm (the points correspond to the experiments reported in Table 3 ). 
Other calculations can be achieved using a mixture of new $\mathrm{Cr}$ sources and ammonia but the only difference in the input data is the $\mathrm{C}$ and $\mathrm{H}$ concentration which changes slightly with the formula of the ligand and consequently the deposition diagram are not drastically modified.

\begin{tabular}{|l|l|l|l|}
\hline $\mathrm{NH}_{3} / \mathrm{Cr}\left(\mathrm{C}_{6} \mathrm{H}_{6}\right)_{2}$ & $\begin{array}{l}\text { Thermodynamic } \\
\text { prediction }\end{array}$ & X-ray Diffraction & $\begin{array}{l}\text { Electron Probe } \\
\text { Micro-Analysis }\end{array}$ \\
\hline \hline 240 & $\mathrm{CrN}+\mathrm{C}$ & $\mathrm{CrN}$ & $\mathrm{CrN}_{1.03} \mathrm{C}_{0.05}$ \\
180 & $\mathrm{CrN}+\mathrm{Cr}_{2}(\mathrm{~N}, \mathrm{C})+\mathrm{C}$ & $\mathrm{CrN}$ & $\mathrm{CrN}_{1.10} \mathrm{C}_{0.05}$ \\
50 & $\mathrm{CrN}+\mathrm{Cr}_{2}(\mathrm{~N}, \mathrm{C})+\mathrm{C}$ & $\mathrm{CrN}+\mathrm{Cr}_{2}(\mathrm{~N}, \mathrm{C})$ & $\mathrm{CrN}_{0.97} \mathrm{C}_{0.14}$ \\
20 & $\mathrm{Cr} 2(\mathrm{~N}, \mathrm{C})+\mathrm{C}$ & $\mathrm{Cr} 2(\mathrm{~N}, \mathrm{C})$ & $\mathrm{Cr}_{2}\left(\mathrm{~N}_{0.47} \mathrm{C}_{0.53) 1.1}\right.$ \\
12.5 & $\mathrm{Cr} 2(\mathrm{~N}, \mathrm{C})+\mathrm{Cr} 3 \mathrm{C}_{2}+\mathrm{C}$ & multi-phased & $\mathrm{CrN}_{0.15} \mathrm{C}_{0.38}$ \\
0 & $\mathrm{Cr} 3 \mathrm{C}_{2}+\mathrm{C}$ & $\mathrm{Cr} 7 \mathrm{C} 3+\mathrm{Cr}_{3} \mathrm{C}_{2}$ & $\mathrm{Cr}_{0.62} \mathrm{C}_{0.38}$ \\
\hline
\end{tabular}

Table 3: Composition of the chromium nitride coatings deposited using the mixture $\mathrm{Cr}\left(\mathrm{C}_{6} \mathrm{H}_{6}\right)_{2} / \mathrm{NH}_{3}$ at $527{ }^{\circ} \mathrm{C}$ and $5 \times 10^{-3}$ atm: comparison between the thermodynamic prediction and the experimental results [68].

\subsection{MOCVD of CoGa: selection of the ligands}

Thermodynamically stable and coherent metal/semiconductor interfaces are necessary in electronic devices. For this purpose, we recently report the epitaxial growth of $\beta$-CoGa on GaAs by MOCVD [69]. Like for the deposition of III-V semiconductor compounds, two strategies compete for the selection of the molecular precursors: (i) a single source precursor containing both $\mathrm{Co}$ and $\mathrm{Ga}$ either directly bonded or linked by a bridging ligand (the composition of the precursor may be the dominant factor for an epitaxial process) or ( $i$ ) the use of separate sources, one for the $\mathrm{Ga}$ and the other for the Co.

Because most of the potential organometallic compounds usable as single source precursor $[52,70]$ or as Co source [71] contain carbonyl groups, we decided to determine the influence of the oxygen on the composition of these intermetallic films. For this goal, a preliminary thermodynamic analysis of the system $\mathrm{Co}, \mathrm{Ga}, \mathrm{C}, \mathrm{H}, \mathrm{O}$ has been undertaken. The calculation was performed using 29 gaseous species, 12 solid phases and one liquid phase (Ga). Comparison of the deposition diagrams in the system $\mathrm{Co}, \mathrm{Ga}, \mathrm{C}, \mathrm{H}$ ( simulating the mixture $\mathrm{CoCp}_{2} / \mathrm{GaEt}_{3}$ ) and $\mathrm{Co}, \mathrm{Ga}, \mathrm{C}, \mathrm{H}, \mathrm{O}$ (simulating the mixture $\mathrm{CoCp}(\mathrm{CO})_{2} / \mathrm{GaEt}_{3}$ ) reveals that $\mathrm{Ga}_{2} \mathrm{O}_{3}$ is the only oxide stable in the MOCVD conditions. Typically, under atmospheric pressure, the desired cubic phase $\beta$-CoGa is obtained for an input gas phase ratio $\mathrm{Ga}$ :Co $\approx 1$ for both chemical systems. The composition of the $\beta-\mathrm{CoGa}$ phase can be monitored from the gas phase composition between the limits dictated by the phase diagram (35-64 Ga at\%). An excess of the Co source leads to a contamination of the films by the solid solution $\alpha$-CoGa whereas an excess of GaEt3 leads to a contamination by $\mathrm{CoGa}_{3}$ using $\mathrm{CoCp}_{2} / \mathrm{GaEt}_{3}$ and $\mathrm{CoGa}_{3}+\mathrm{Ga}_{2} \mathrm{O}_{3}$ using $\mathrm{CoCp}(\mathrm{CO})_{2} / \mathrm{GaEt}_{3}$. This analysis is in satisfactory agreement with our experimental observations [69].

The theoretical influence of the deposition temperature and the total pressure using both systems have been investigated for an input gas composition $\mathrm{Ga}: \mathrm{Co}=1$. The results provide also fruitful informations for the use of single sources having nearly the same initial composition. Thus, a high partial pressure of hydrogen is necessary to avoid a $\mathrm{C}$ contamination and to deposit pure single phased $\beta$-CoGa films (typically $\mathrm{H}_{2} / \mathrm{Co} \approx 100$ ). Under atmospheric pressure a codeposition of $\mathrm{Ga}_{2} \mathrm{O}_{3}$ occurs at low temperature $\left(\leq 300^{\circ} \mathrm{C}\right)$ using $\mathrm{CoCp}(\mathrm{CO})_{2} / \mathrm{GaEt} 3$. Above $620^{\circ} \mathrm{C}$ a multi-phase material grows from both systems $(\beta-\mathrm{CoGa}+\mathrm{CoGa} 3+\mathrm{C})$. 
Both to compensate the poor volatility of precursors (specially that of single sources) and to increase their diffusivity, MOCVD experiments are frequently performed under reduced pressure. Fig. 4 shows clearly that the lower the pressure, the higher the $\mathrm{C}$ contamination of the film. However, hydrogen allows to overcome this problem likely by reaction with the carbon to form methane. It is noteworthy to note that the existence range of pure $\beta-\mathrm{CoGa}$ is significantly increased towards the low pressures in presence of small amount of oxygen brought by the carbonyl groups. Then, $\mathrm{CO}$ groups are beneficial to run the process under low pressure since they facilitate the removal of the adventitious $\mathrm{C}$ in the form of $\mathrm{CO}$ and $\mathrm{CO}_{2}$. This preliminary calculation is supported by recent experimental results. Indeed, CoGa polycrystalline films were successfully deposited under low pressure using the single source precursors (CO) $4 \mathrm{CoGaCl}_{2}$ (THF) [70] and [(py)(Et)Co(dmg.GaEt2) 2 ] [52] which have an atomic ratio $\mathrm{Ga}$ :Co fixed to 1 and 2, respectively. Furthermore, there is a direct bond between the two metals in the first one, whereas they are associated by a chelating ligand in the second one. The film have the same stoichiometry than the precursor indicating that direct bond between the desired elements is not required for this system.

(a)

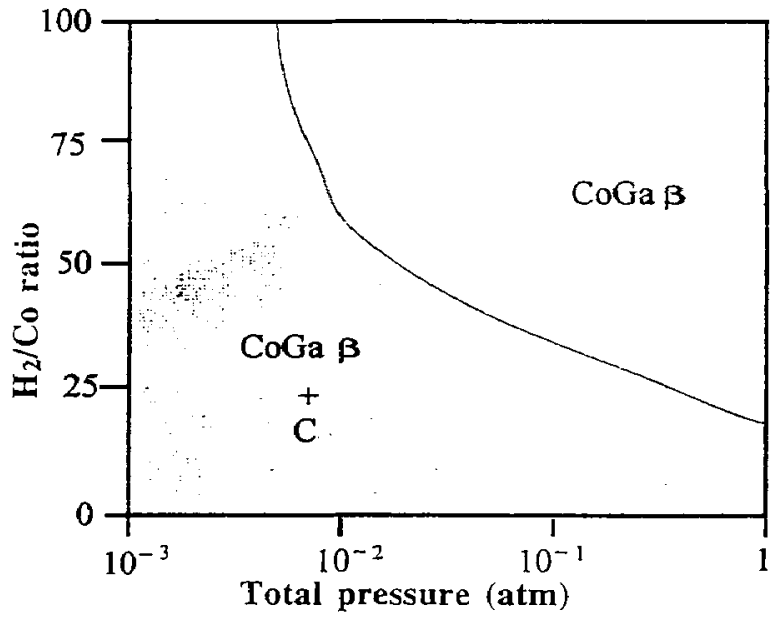

(b)

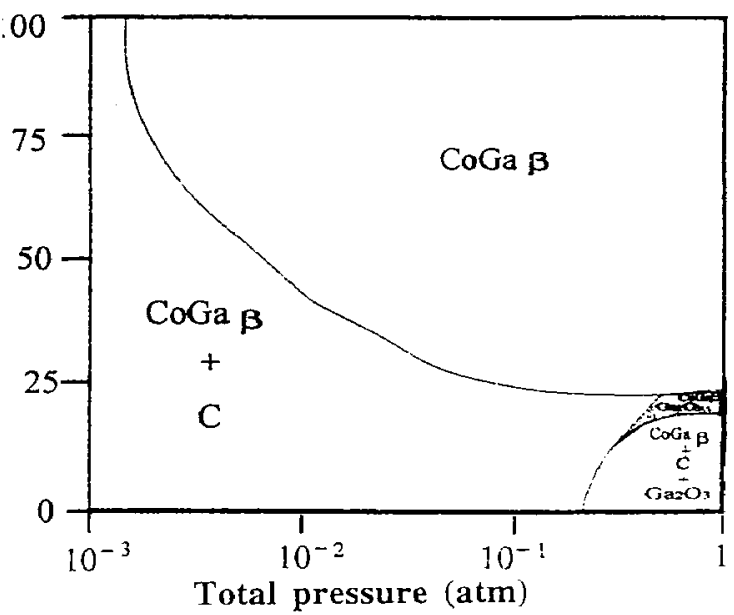

Fig. 4: Influence of the total pressure and the atomic ratio $\mathrm{H}_{2} / \mathrm{Co}$ on the nature of the solid phases deposited using $\mathrm{CoCp}_{2} / \mathrm{GaEt}_{3}$ (a) and $\mathrm{CoCp}(\mathrm{CO})_{2} / \mathrm{GaEt}_{3}$ (b). Calculations were done at $300^{\circ} \mathrm{C}$ and using an input atomic ratio $\mathrm{Ga}: \mathrm{Co}=1$.

\section{CONCLUSION}

Metal-organic compounds are extensively used as molecular precursor in MOCVD owing to their volatility and their low thermal stability that allows to deposit a great variety of thin film materials at low temperature. However, the design and the selection of suitably tailored metalorganic precursor is a fundamental key to develop successfully new MOCVD processes. I have attempted in this paper to rationalize and to discuss the criteria of selection from literature data and my own experience. 
The fundamental requirements listed for an ideal precursor may be completed or slightly modified depending on the constraints for the process (epitaxial growth, UV activation, nature of the substrate...). These stringent requirements are almost impossible to fulfil simultaneously. Therefore a metal-organic compounds will be suitable when it will fulfil the most important requirements: usually, a sufficient volatility and a good ability to be cleanly decomposed.

Then a limiting step for the MOCVD process is the understanding of the growth mechanisms. Indeed, a better knowledge of the reaction pathways is required to improve the selection of the molecular precursors and, subsequently, to control the carbon incorporation in the films which is the main drawback of the process.

A single source metal-organic precursor is an attractive route for the deposition of a multicomponents material. If the growth is kinetically controlled (labile organic ligands bound to a cluster core), the structure of the single source is the dominant feature and the structure of the deposited material is strongly influenced by the precursor structure (growth of metastable materials possible). If the process is controlled by the diffusion (e.g. epitaxial growth) the dominant factor of the single source precursor is its composition. Although most of MOCVD processes are kinetically controlled due to the low temperature, we have seen using two examples, that thermodynamic calculations provides fruitful informations for the selection of precursors (use or not of a single source for the deposition of chromium nitride and choice of the ligands for MOCVD of CoGa).

\section{Acknowledgments}

I gratefully ackowledge Dr. C. Bernard (Grenoble) and Dr. F. Schuster for their contribution to the $\mathrm{Cr}-\mathrm{N}$ work and Prof. H. D. Kaesz (UCLA) and S. Astié for their participation to the study on CoGa. This work was partially supported by the CNRS under a Contract of Research Program (CPR) with DRET, AEROSPATIALE, ASCOMETAL and GIAT Industries.

\section{References}

[1] Stringfellow G. B., J. Electron. Mater. 17 (1988) 327-335.

[2] Cowley A. H. and Jones R. A., Angew. Chem. Int. Ed. Engl. 28 (1989) 1208-1215.

[3] Maury F., Adv. Mater. 3 (1991) 542-548.

[4] Kodas T. and Hampden-Smith M., The Chemistry of Metals CVD (VCH Verlagsgesellschaft mbH, Germany, 1994).

[5] Girolami G. S. and Gozum J. E., Mat. Res. Soc. Symp. Proc. 158 (1990) 319-329.

[6] Schleich D. M., J. Phys. Coll., sup. C5, 50 (1989) 961-979.

[7] Ozawa T., Thermochimica Acta 174 (1990) 185-199.

[8] Hails J. E., Irvine S. J. C. and Mullin J. B., Mat. Res. Soc. Symp. Proc. 161 (1990) 343-349.

[9] Kayser O., Heinecke H., Brauers A., Lüth H. and Balk P., Chemtronics 3 (1988) 90-93.

[10] Battat D., Faktor M. M., Garret I. and Moss R. H., J. C. S. Farad. Trans. I 70 (1974) 2267.

[11] Hawker D., Chemosphere 25 (1992) 427-436.

[12] Knauf J., Schmitz D., Strauch G., Jurgensen M., Heyen M. and Melas A., J. Cryst. Growth 93 (1988) 34.

[13] Bradley D. C., Chudzynska H. and Frigo D. M., Chemtronics 3 (1988) 159.

[14] Tel'Noi V. I., Rabinovich I. B., Latyaeva V. N. and Lineva A. N., Dokl. Akad. Nauk SSSR 197 (1971) 1348.

[15] Wilkinson G:, Cotton F. A. and Birminghan J. M., J. Inorg. Nucl. Chem. 2 (1956) 95.

[16] Kaplan L., Kester W. L. and Katz J. J., J. Am. Chem. Soc. 74 (1952) 5531.

[17] Torrez-Gomez L. A., Barreiro-Rodriguez G. and Mendez-Ruiz F., Thermochimica Acta 124 (1988) 179. 
[18] Turnbull A. G., Austral. J. Chem. 20 (1967) 2757.

[19] Fischer E. O. and Grubert H., Chem. Ber. 92 (1959) 2302.

[20] Hull H. S., Reid A. F. and Turnbull A. G., Austral. J. Chem. 18 (1965) 249.

[21] Xue Z., Thridandam H., Kaesz H. D. and Hicks R. F., Chem. Mater. 1 (1992) 162-166.

[22] Maury F., Appl. Organometal. Chem. 6 (1992) 619-626.

[23] Kaesz H. D., Williams R. S., Hicks R. F., Zink J. I., Chen Y-J., Müller H-J., Xue Z. Xu D., Shuh D. K. and Kim Y. K., New J. Chem. 14 (1990) 527-534.

[24] Jones A. C., Chemtronics 4 (1989) 15-25.

[25] Moore A. H., Scott M. D., Davies J. I., Bradley D. C., Faktor M. M. and Chudzynska H., J. Cryst. Growth 77 (1986) 19.

[26] Foster D. F., Rushworth S. A., Cole-Hamilton D. J., Jones A. C. and Stagg J. P., Chemtronics 3 (1988) 38.

[27] Gladfelter W. L., Boyd D. C. and Jensen K. F., Chem. Mater. 1 (1989) 339-343.

[28] Brauers A., Weyers and P. Balk, Chemtronics 4 (189) 8-14.

[29] Omstead T. R. and Jensen K. F., Chem. Mater. 2 (1990) 39.

[30] Maury F., Bouabid K., Fazouan N., Gué A. M. and Estève D., Applied Surf. Sci. 86 (1995) 447-452.

[31] Jones A. C., J. Phys. IV, Coll. C2, 1 (1991) 253-261.

[32] Chaterjee A. K., Faktor M. M., Moss T. H. and White E. A. D., J. Phys., Coll. C5, sup. 12, 43 (1982) 491.

[33] Molassioti A., Moser M., Stapor A., Scholz F., Hostakek M. and Pohl L., Appl. Phys. Lett. 54 (1989) 857.

[34] Jones R. A., Cowley A. H., Benac B. L., Kidd K. B., Ekerdt J. G and Miller J. E., Mat. Res. Soc. Symp. Proc. 131 (1989) 51-57.

[35] Jensen K. F., Annapragada A., Ho K. L., Huh J.-S., Patnaik S. and Salim S., J. Phys. IV, Coll. C2, 1 (1991) 243-252.

[36] Kuech T. F., Semicond. Sci. Technol. 8 (1993) 967 (and references therein).

[37] Trundle C. and Brierley C. J., Appl. Surf. Sci. 36 (1989) 102-118.

[38] Truex T. J., Saillant R. B. and Monroe F. M., J. Electrochem. Soc. 122 (1975) 1396.

[39] Pawlyk P., US Patent 2685532 (1954).

[40] Lander J. J. and Germer L. H., Am. Inst. Mining Met. Eng., Tech. Publ. 2259, Sept. (1947).

[41] Owen B. B. and Webber R. T., Trans. Am. Inst. Mining Eng. 175 (1948) 693.

[42] Nutt S. R. and Wawner F. E., Ceram. Eng. Sci. Proc. 2 (1981) 840.

[43] Blocher J. M. Jr., "Chemical Vapor Deposition", Deposition Technologies for films and Coatings, Developments and Applications, R. F. Bunshah (Ed.), (Noyes Publications, Park Ridge, NJ, 1982) p. 338.

[44] Polikarpov V. B., Lusin A. S., Dodonov V. A. and Klement'ev E. K., Isv. Akad. Nauk SSSR, Neorg. Mater. 20 (1984) 1839.

[45] Gueroudji L., Maury F. and Vahlas C., Proc. of T.M.S., Cleaveland, OH, Oct. 29-Nov. 2 (1995) submitted.

[46] Hoke J. B., Stern E. W. and Murray H. H., J. Mater. Chem. 1 (1991) 551-554.

[47] Zinn A., Niemer B. and Kaesz H. D., Adv. Mater. 4 (1992) 375-378 (and references therein)

[48] Ceyer S. T., Science 249 (1990) 133.

[49] Niemer B., Zinn A., Stovall W. K., Gee P. E., Hicks R. F. and Kaesz H. D., Appl. Phys. Lett. 61 (1992) 1793.

[50] Fischer H. E., Larkin D. J. and Interrante L. V., Mat. Res. Soc. Bulletin, 16 (1991) 59-65. 
[51] MacInnes A. N., Power M. B. and Barron A. R., Chem. Mater. 4 (1992) 11-14.

[52] Fraser B., Brandt L., Stovall W. K., Kaesz H. D., Khan S. I. and Maury F., J. Organometal. Chem. 472 (1994) 317-328.

[53] Bernard C., Deniel Y., Jacquet A., Vay P. and Ducarroir M., J. Less Com. Met. 40 (1975) 165.

[54] Bernard C. and Madar R., Mat. Res. Soc. Symp. Proc. 168 (1990) 3.

[55] Schuster F., Schouler M. C., Bernard C., Maury F., Morancho R. and Nowak J. F., Proceed. 11 th Int. Conf. on CVD, K. E. Spear and G. W. Cullen Eds., (The Electrochem. Soc., Pennington, 1990) pp.113-119.

[56] SGTE data bank (Scientific Group Thermodata Europe), Saint Martin d'Hères, France.

[57] Schuster F., Maury F. and Nowak J. F., Surf. Coatings Technol. 43-44 (1990) 185.

[58] Nowak J. F., Duret-Thual C., Maury F. and Oquab D., Proc. Int. Coll. on Wear and Resistant Materials, Bull. Cercle d'Etude des Métaux 15 (1987) 14.1-14.11.

[59] Rutherford N. M., Larson C. E. and Jackson R. L., Mat. Res. Soc. Symp. Proc. 131 (1989) 439-445.

[60] Sugiyama K., Pac S., Takahashi Y. and Motojima S., J. Electrochem. Soc. 122 (1975) 15451549.

[61] Fix R. M., Gordon R. G. and Hoffman D. M., Chem. Mater. 2 (1990) 235-241.

[62] Fix R., Gordon R. G. and Hoffman D. M., Chem. Mater. 3 (1991) 1138-1148.

[63] Dubois L. H., Zegarski B. R. and Girolami G. S., J. Electrochem. Soc., 139 (1992) 36033609.

[64] Fix R., Gordon R. G. and Hoffman D. M., Chem. Mater. 5 (1993) 614-619.

[65] Bonnefond P., Feurer R., Reynes A. and Maury F., "Metal Organic Chemical Vapor Deposition of vanadium carbonitride coatings", Advances in Inorganic Films and Coatings, P. Vincenzini Ed. ( Techna srl, Faenza, Italy, 1995) pp. 207-214.

[66] Weiller B. H. and Partido B. V., Chem. Mater. 6 (1994) 260-261.

[67] Prybyla J. A., Chiang C.-M. and Dubois L. H., J. Electrochem. Soc. 140 (1993) 2695-2702.

[68] Schuster F., Maury F., Nowak J. F. and Bernard C., Surf. Coatings Technol. 46 (1991) 275-288.

[69] Maury F., Talin A. A., Kaesz H. D. and Williams R. S., Chem. Mater. 5 (1993) 84-89.

[70] Maury F., Brandt L. and Kaesz H. D., J. Organomet. Chem. 449 (1993) 159-165.

[71] Fau F. and Maury F., "Growth and characterization of Co coatings deposited by MOCVD below $120^{\circ} \mathrm{C}$ using $\mathrm{CO}_{2}(\mathrm{CO}) 8^{\prime \prime}, 3$ rd Inter. Symp. on Trends and New Applications in Thin Films, Le Vide, les Couches Minces, sup. 259 (Sociéte Française du Vide, Paris, 1991) pp. 95-97 (and references therein). 